\title{
Nose-to-Brain Delivery by Nanosuspensions- Based in situ Gel for Breviscapine
}

This article was published in the following Dove Press journal:

International Journal of Nanomedicine

\author{
Yingchong Chen' \\ Yuling Liu ${ }^{2}$ \\ Jin Xie' \\ Qin Zheng' \\ Pengfei Yue' \\ Liru Chen ${ }^{3}$ \\ Pengyi Hu' \\ Ming Yang'
}

'Key Laboratory of Modern Preparation of TCM, Ministry of Education, Jiangxi University of Traditional Chinese Medicine, Nanchang 330004, People's Republic of China; ${ }^{2}$ Institute of Chinese Materia Medica, China Academy of Chinese Medical Sciences, Beijing 100700 , People's Republic of China; ${ }^{3}$ Beijing Hospital, Beijing 100730, People's Republic of China
Correspondence: Pengfei Yue; Ming Yang Key Laboratory of Modern Preparation of TCM, Ministry of Education, Jiangxi University of Traditional Chinese Medicine, 1688 Meilingdadao Road, Nanchang 330004, People's Republic of China

$\mathrm{Tel} / \mathrm{Fax}+8679187 / 18658$

Email ypfpharm@126.com;

yangming_215@163.com
Purpose: Nose-to-brain drug delivery is an effective approach for poorly soluble drugs to bypass the blood-brain barrier. A new drug intranasal delivery system, a nanosuspensionbased in situ gel, was developed and evaluated to improve the solubility and bioavailability of the drug and to prolong its retention time in the nasal cavity.

Materials and Methods: Breviscapine (BRE) was chosen as the model drug. BRE nanosuspensions (BRE-NS) were converted into BRE nanosuspension powders (BRE-NP). A BRE nanosuspension in situ gelling system (BRE-NG) was prepared by mixing BRE-NP and $0.5 \%$ gellan gum $(\mathrm{m} / \mathrm{v})$. First, the BRE-NP were evaluated in terms of particle size and by differential scanning calorimetry (DSC), powder X-ray diffraction (PXRD), scanning electron microscopy (SEM) and transmission electron microscopy (TEM). Subsequently, the critical ionic concentration of the gellan gum phase transition, influence of the deacetylated gellan gum (DGG) concentration on the expansion coefficient (S\%), water-holding capacity, rheological properties and in vitro release behaviour of the BRE-NG were investigated. The pharmacokinetics and brain distribution of the BRE-NG after intranasal administration were compared with those of the intravenously injected BRE-NP nanosuspensions in rats.

Results: The rheology results demonstrated that BRE-NG was a non-Newtonian fluid with good spreadability and bioadhesion performance. Moreover, the absolute bioavailability estimated for BRE-NG after intranasal administration was $57.12 \%$. The drug targeting efficiency (DTE\%) of BRE in the cerebrum, cerebellum and olfactory bulb was 4006, 999 and 3290, respectively. The nose-to-brain direct transport percentage (DTP\%) of the cerebrum, cerebellum and olfactory bulb was $0.975,0.950$ and 0.970 , respectively.

Conclusion: It was concluded that the in situ gel significantly increased the drug retention time at the administration site. Therefore, the nanosuspension-based in situ gel could be a convenient and effective intranasal formulation for the administration of BRE.

Keywords: nose-to-brain, nanosuspensions, in situ gel, breviscapine, brain distribution

\section{Introduction}

Recently, stroke has become the second leading cause of death and the third leading cause of disability worldwide, and ischemic stroke accounts for $85 \%$ of all strokes. Ischemic stroke is mainly caused by a blood clot preventing blood flow to the brain. ${ }^{1,2}$ Current therapies for ischemic stroke are to remove the blockage chemically with tissue plasminogen activator (t-PA) or mechanically. ${ }^{3}$ However, t-PA has a narrow therapeutic window and is associated with potentially severe hemorrhagic complications, and the therapeutic efficacy of t-PA is still limited; only $3 \%$ of patients can receive this treatment. ${ }^{4}$ Various approaches have been developed for ischemic stroke treatment. Therefore, developing a safe and effective way to deliver drugs to the brain is urgently 
needed. The main obstacle for the treatment of CNS diseases is the presence of the blood-brain barrier (BBB), which actively prevents the accumulation of drugs into the brain. $^{5,6}$ It is well known that the intranasal route may be an effective strategy of circumventing the blood-brain barrier to deliver components directly. As an effective non-invasive route for the treatment of brain diseases, intranasal administration has received increasing attention in the clinic. ${ }^{7,8}$ Different drug delivery systems have been applied to improve the nasal permeability and mucoadhesive properties, including liposomes, polymeric micelles, and microspheres. ${ }^{9}$

Nanosuspensions (NS) hold tremendous potential for nose-to-brain drug due to increasing the absorption and bioavailability of many poorly soluble drugs by intranasal administration. Nanosuspensions are considered a dispersion of drug nanoparticles in suitable polymers and/or surfactants with sizes lower than $1 \mu \mathrm{m}$ (most commonly between 200 and $500 \mathrm{~nm}$ ). ${ }^{10,11}$ Because of the small particle size and large surface area, NS offer some advantages for enhancing the solubility and dissolution velocity of poorly soluble drugs. ${ }^{12,13}$ However, liquid suspensions suffer from short retention times in the nasal cavity due to rapid mucociliary clearance. This problem can be solved by using smart stimuli-responsive systems. ${ }^{14}$ Among these systems, the in situ gelling formulation is one of the most commonly used techniques. After intranasal administration, triggered either by physiological factors (temperature, ion concentration, water content), the solution is transformed into a gel, which allows for a more accurate administered dose. ${ }^{15}$ These in situ gels for intranasal administration have been reported to enhance the drug delivery efficiency by increasing the nasal retention time and offer many advantages, such as simple preparation process and good permeability of therapeutic agents. ${ }^{16}$ Therefore, nanosuspensions embedded in an in situ gel appear to be an interesting strategy for nose-to-brain delivery of poorly soluble drugs, which can combine the advantages of both the nanosuspensions and the in situ gel.

Breviscapine (BRE) is a mixture of flavonoid glycosides that is isolated from the Chinese herb Erigeron breviscapus (Vant.), and its structure is shown in Figure 1. ${ }^{17-19}$ BRE has gained considerable attention due to its therapeutic effects, including anticoagulation, improving microcirculation, and activating blood supply to the heart and brain. ${ }^{20,21}$ BRE has been extensively used for the treatment of cerebrovascular and cardiovascular diseases and has been even more efficient in the treatment of ischemic stroke and coronary heart disease. ${ }^{22,23}$ Currently, BRE has been developed into various

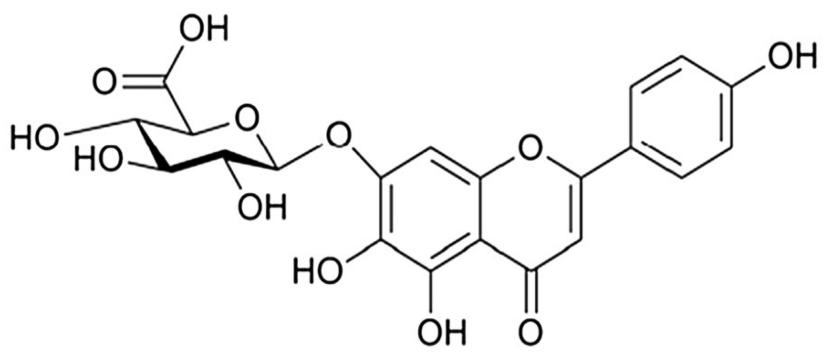

Figure I The structure of Breviscapine.

pharmaceutical dosage forms for therapy, including tablets, granules, chewable tablets, drop pills and injections, and it has been used in clinical practice for a long time in China. ${ }^{24}$ However, its poor solubility, poor oral bioavailability and short plasma half-life limit its clinical application. ${ }^{25}$ To solve these problems, various strategies have been explored such as liposomes and lipid emulsions. ${ }^{26,27}$ Although the solubility and dissolution of BRE were significantly improved based on these technologies, the drug safety and drug loading ability of these formulation technologies were not sufficient.

To improve the solubility of BRE and prolong its retention time in the nasal cavity, this study developed a new delivery system for intranasal administration combining the advantages of nanosuspensions and in situ gel. The aims of the present study were to prepare Tween 80-stabilized BRE nanosuspensions (BRE-NS) and to further transform BRENS into BRE nanosuspension powders (BRE-NP) with excellent redispersibility via spray-drying. A BRE nanosuspension in situ gelling system (BRE-NG) could be prepared by using deacetylated gellan gum as the gel substrate. The formulations were investigated with respect to the in vitro release, in vivo pharmacokinetics and brain distribution of the BRE-NG.

\section{Materials and Methods \\ Materials}

Breviscapine was purchased from Nanjing Zelang Biotechnology Co., Ltd. (Purity > 98\%, Nanjing, People's Republic of China). Scutellarin and telmisartan reference substances were obtained from the National Institute for the Control of Pharmaceutical and Biological Products (Beijing, People's Republic of China). Tween 80 was obtained from JiangSu ChenPai Pharmaceutical Group Co. (HaiMen, People's Republic of China). Mannitol was obtained from Chineway Pharmaceutical Tech., Co., Ltd. (Shanghai, 
People's Republic of China). Deacetylated gellan gum was obtained from Sigma-Aldrich (Saint Louis, MO, USA).

\section{Animals}

Male Sprague-Dawley rats ( 7 weeks old, $200 \pm 20 \mathrm{~g}$ ) were purchased from Hunan SJA Laboratory Animal Co., Ltd. (Hunan, People's Republic of China; SYXK 2016-0002). All animal experiments were carried out in accordance with the Guide for the Care and Use of Laboratory Animals of the National Research Council. The protocol was approved by the Institutional Animal Care and Use Committee of Jiangxi University of Traditional Chinese Medicine. Rats were given a standard diet and water. The animals were kept under standard conditions (room temperature $22^{\circ} \mathrm{C}$ and $50 \%$ humidity) with a regular $12: 12$ hour light-dark cycle throughout the experimental period.

\section{Preparation of BRE-NS}

The BRE-NS were prepared by using the high-pressure homogenization method. First, $0.5 \mathrm{~g}$ BRE and 0.05 g Tween 80 were dispersed in $100 \mathrm{~mL}$ of double-distilled water, and the raw mixture suspension was stirred using a high shear homogenizer at 22,000 rpm for $3 \mathrm{~min}$ (FA25, Fluko Equipment Shanghai Co, Ltd, Shanghai, People's Republic of China). Subsequently, the raw mixture suspensions were subjected to homogenization using a piston-gap high-pressure homogenizer with different pressures (200, $400,600,800$ bar) for 10 cycles and then 60 cycles at 1000 bar (AH-1000D, ATS Engineering Inc., Seeker, Canada). Finally, the BRE-NS was collected after homogenization.

\section{Spray-Drying of BRE-NS}

Ostwald ripening often leads to flocculation, aggregation or crystal growth due to the thermodynamic instability of the nanosuspensions. ${ }^{28}$ The spray-drying technique is usually used as an alternative to improve the stability of nanosuspensions by means of their conversion into dried nanocrystal powders. ${ }^{29}$ The BRE-NS were spray-dried with a Buchi mini spray-dryer (model B290, Buchi Labortechnik AG, Flawil, Switzerland). Mannitol was added to BRE-NS to facilitate spray-drying. The drying conditions were set as follows: the inlet temperature was set as $110^{\circ} \mathrm{C}$; the aspiration rate was set as $90 \%$; the solution flow rate was set as $5 \mathrm{~mL} / \mathrm{min}$, and BRE nanosuspension powder (BRE-NP) was collected from the separation chamber. The powders were stored in sealed glass vials and kept under refrigeration for further investigations.

\section{Preparation of BRE-NG}

A certain amount of deacetylated gellan gum (DGG) was dispersed into double-distilled water and completely dissolved by heating to $90^{\circ} \mathrm{C}$ using a collecting thermostatic heating magnetic stirrer and slowly cooling to $40^{\circ} \mathrm{C}$. Then, glycerol $(1 \%, w / v)$ and ethyl4-hydroxybenzoate $(0.02 \%$, $\mathrm{w} / \mathrm{v})$ were added and mixed well. The $\mathrm{pH}$ of the formulation was adjusted to 6.0 using tromethamine. DGG was added as a gel matrix, glycerol was added as a humectant and ethyl4-hydroxybenzoate was added as a preservative. Diazolidinyl urea $(0.3 \%, \mathrm{w} / \mathrm{v})$ was added as a preservative. Then, BRE-NP was added into the DGG solution until well-blended.

\section{Characterization BRE-NP}

\section{Particle Size Measurements of BRE-NP}

The particle size distributions of the BRE-NS and BRENP were measured by a Mastersizer Micro Plus (Malvern Instruments Limited, Worcestershire, UK) by the wet method. Analysis of the diffraction patterns was performed using the Mie model (standard presentation: dispersant refractive index $=1.55$, real particle refractive index $=$ 1.670, imaginary particle refractive index $=0.01$ ). All measurements were performed in triplicate.

\section{Differential Scanning Calorimetry (DSC)}

The peak melting temperatures of raw BRE, BRE-NP, mannitol and the mixture of raw BRE with mannitol were assessed using DSC (Diamond DSC, Perkin-Elmer, USA). The powder sample ( $2-4 \mathrm{mg}$ ) was weighed before being placed in a sealed perforated aluminium pan and heated in an aluminium pan from $40^{\circ} \mathrm{C}$ to $300^{\circ} \mathrm{C}$ at a heating rate of $10^{\circ} \mathrm{C} / \mathrm{min}$ under a nitrogen gas atmosphere. Indium standards were used to calibrate the DSC temperature and enthalpy scale.

\section{Powder X-Ray Diffraction (PXRD)}

The PXRD analysis of BRE, BRE-NP, mannitol and the mixture of raw BRE with mannitol was analysed using PXRD (PANalytical, Westborough, MA, USA). The samples were irradiated with monochromatized $\mathrm{Cu} \mathrm{K} \alpha$ radiation and analysed between $0^{\circ}$ and $90^{\circ} 2 \theta$ at a scan rate of $1 \%$ min. Measurements were performed at voltages of 40 $\mathrm{kV}$ and $25 \mathrm{~mA}$.

\section{Scanning Electron Microscopy (SEM)}

The morphological analysis of raw BRE and BRE-NP was conducted by scanning electron microscopy (Quanta 250, 
FEI, USA). The samples were coated with a thin layer of gold before scanning.

\section{Transmission Electron Microscopy (TEM)}

TEM measurement of the BRE-NP was conducted using a JEM-1200EX (JEOL, Tokyo, Japan). A drop of the BRE-NP nanosuspension was diluted with doubledistilled water and placed onto a copper grid. The copper grid was then negatively stained using a $2 \%$ solution of phosphotungstate acid for 5 min. After absorption of any excess liquid, the sample was dried naturally at room temperature.

\section{Characterization and in vitro Drug Release of BRE-NG Critical lonic Concentration of the Gellan Gum Phase Transition}

The critical ionic concentration (CIC) is an important index of ion-activated in situ gels. A certain amount of DGG $(0.2 \%-1 \%, \mathrm{w} / \mathrm{v})$ in solution $(2.0 \mathrm{~mL})$ was blended with various amounts of artificial nasal fluid (ANF) (0.1-1 mL) in vials. The artificial nasal fluid (ANF) consisting of 150 $\pm 32 \mathrm{mM} \mathrm{Na}^{+}, 41 \pm 18 \mathrm{mM} \mathrm{K}^{+}$, and $4 \pm 2 \mathrm{mM} \mathrm{Ca}^{+}$was consistent with previous reports. ${ }^{30}$ The optimal gel matrix was chosen according to the viscosity and gelatine capacity (after $30 \mathrm{~s}$, vials were turned over and observed for their gelation). If the gels adhered to the bottom instead of flowing or sliding down the side, the formulation was considered a gel and denoted with "+". Flowing or slipping gels were denoted with “_", whereas formulations with intermediate behaviours were denoted with " \pm ". The minimum concentration at which the transformation from solution to gel occurred was considered the CIC. ${ }^{30}$

\section{Influence of the DGG Concentration on the Expansion Coefficient (S\%) of BRE-NG}

The S\% was determined by mixing $1 \mathrm{~mL}$ of the different concentrations of DGG solutions with $0.25 \mathrm{~mL}$ ANF in a graduated test tube, which was placed in a $32^{\circ} \mathrm{C}$ water bath; the total liquid volume, $\mathrm{V}_{1}$, was $1.25 \mathrm{~mL}$. After adding $2.0 \mathrm{~mL}$ of $\mathrm{ANF}$, the total volume was $\mathrm{V}_{\mathrm{T}}$. Thus, the volume of the in situ gel was. The expansion coefficient was $\mathrm{S} \%=\left(\mathrm{V}_{\mathrm{G}}-\mathrm{V}_{1}\right) / \mathrm{V}_{1} \times 100 \% .^{30,31}$

\section{Water-Holding Capacity of BRE-NG}

The water-holding capacity of BRE-NG was measured by the centrifugal method. ${ }^{32}$ The water-holding capacity was determined by mixing $2 \mathrm{~mL}$ of different concentrations of DGG solutions with $0.6 \mathrm{~mL}$ of ANF, which was placed into preweighed tubes. The weight of the in situ gels during this stage was considered the initial weight $\left(\mathrm{W}_{0}\right)$. The BRE-NG was centrifuged at $8,000 \mathrm{~g}$ at $4^{\circ} \mathrm{C}$ for $15 \mathrm{~min}$, the water on the surface was absorbed with filter paper, and the gel weight $\left(\mathrm{W}_{1}\right)$ was determined after centrifugation. The water-holding capacity $=\mathrm{W}_{1} / \mathrm{W}_{0} \times 100 \%$.

\section{Rheological Evaluation of BRE-NG}

The rheological properties of the BRE-NG were investigated. Viscosity, thixotropy, and oscillation tests were performed using a Physica MCR101 rheometer system (Anton Paar $\mathrm{GmbH}$, Austria) with a cone-plate sensor (PP50-1) in the OSR model with a stress sweep rate between 3 and $500 \mathrm{~Pa}$ and a constant frequency of $30^{\circ} \mathrm{C}$ at $1 \mathrm{~Hz}$.

\section{In vitro Release Study of BRE-NG}

For the preparation of intranasal administration, the release of drug from the formulation will directly affect the drug absorption site in the nasal cavity. ${ }^{14}$ The in vitro release study of BRE was performed using a Franz diffusion cell apparatus (Tianjin Zhengtong Technology Co., Ltd., Tianjin, People's Republic of China). A semipermeable membrane (Spectra/Por 1 membrane, MWCO: $8000 \sim 14,000$ ) was placed between the donor and the receiver compartment. The upper chamber served as the donor compartment, in which $2 \mathrm{~mL}$ of the BRE-NG and $2 \mathrm{~mL}$ of the BRE-NP suspensions were placed. The receiver compartment was filled with $12 \mathrm{~mL}$ of artificial nasal fluid (ANF). The receiver medium was stirred magnetically at $200 \mathrm{r} \bullet \mathrm{min}^{-1}$ and maintained at a constant temperature of $32 \pm 2{ }^{\circ} \mathrm{C}$. At predetermined time intervals, a sample volume of $2 \mathrm{~mL}$ was taken from the receiver compartment, and an equal volume of fresh ANF was supplemented. Experimental samples were analysed by HPLC (Agilent 1260, USA) using a C-18 reversed-phase column (Elite HPLC, People's Republic of China, $4.6 \mathrm{~mm} \times 250 \mathrm{~mm}, 5$ $\mu \mathrm{m})$. The mobile phase consisted of $45 \%$ methanol and $55 \%$ of a $0.1 \%$ phosphoric acid solution. The flow rate was $1 \mathrm{~mL} / \mathrm{min}$. The UV detector wavelength was $337 \mathrm{~nm}$, and the oven temperature was $25^{\circ} \mathrm{C}$. The injection volume was $20 \mu \mathrm{L} .^{33}$ The experiment was performed in triplicate.

\section{In situ Nasal Absorption of BRE-NG via Intranasal Administration}

To determine the absorption concentration of BRE after intranasal administration, the in situ nasal perfusion technique was used in the study. Male Sprague-Dawley rats (7 weeks old, $200 \pm 20 \mathrm{~g}$ ) were randomized into 4 groups of 
10 animals each. Before experimentation, the rats were anaesthetized with an intraperitoneal injection of chloral hydrate (350 mg/kg body weight). A small transverse incision was made in the neck of the rats, and then the trachea was cannulated with a polyethylene tube (PE-90) to maintain spontaneous respiration. Another PE-90 tube was inserted through the esophagus into the posterior part of the nasal cavity. The nasopalatine duct was closed with an adhesive agent (cyanoacrylate glue) to prevent drainage of the solution from the nasal cavity into the mouth. ${ }^{33}$ The tube inserted into the esophagus was connected to a reservoir containing $5 \mathrm{~mL}$ drug solutions (BRE concentrations of $3,10,50$ and $100 \mathrm{mg} / \mathrm{mL}$, which were placed in a water bath maintained at $37.5^{\circ} \mathrm{C}$ under magnetic stirring). The solution was recirculated from the reservoir through the nasal cavity and out of the nostrils back into the reservoir by means of a peristaltic pump. The flow rate was set to $2 \mathrm{~mL} / \mathrm{min}$. At predetermined time intervals, a sample volume of $100 \mu \mathrm{L}$ was taken from the reservoir, and an equal volume of drug solution was supplemented. The experimental samples were analysed by HPLC.

\section{In vivo Study of BRE-NG}

\section{In vivo Pharmacokinetic and Brain Distribution Studies}

Male Sprague-Dawley rats ( 7 weeks old, $200 \pm 20$ g) were randomized into 2 groups of 42 animals each. Before the experiment, the animals were fasted overnight but allowed to drink water. BRE was intranasally and intravenously administered at a dose of $20 \mathrm{mg} / \mathrm{kg}$. For the intranasal administration group, the rats were anaesthetized with an intraperitoneal injection of chloral hydrate $(350 \mathrm{mg} / \mathrm{kg}$ body weight) and kept in a heated environment to maintain body temperature. A small transverse incision was made in the neck of the rats, and then the trachea was cannulated with a polyethylene tube (PE-90) to maintain spontaneous respiration through esophageal ligation. ${ }^{34}$ Then, $100 \mu \mathrm{L}$ of BRE-NG (50 $\mu \mathrm{L}$ for each nostril) was administered to the nostril with a microsyringe. The intravenous administration group was slowly injected with BRE-NS $(1 \mathrm{~mL})$ via the tail vein. After administration, the rats were sacrificed at $0.833,0.25,0.5,1,2,4$ and $8 \mathrm{~h}$ post dosing $(\mathrm{n}=6)$. A blood aliquot $(0.25 \mathrm{~mL})$ was collected from the orbital vein, and plasma was separated by Sigma $2 \mathrm{~K} 15 \mathrm{C}$ centrifugation at 4,000 rpm for $15 \mathrm{~min}$ and stored at $-81^{\circ} \mathrm{C}$ until analysis. Then, the whole brain was removed from the skull, quickly rinsed with normal saline and wiped with filter paper to remove excess water. It was dissected into three anatomical regions, including the cerebrum, cerebellum and olfactory bulb. All brain samples were stored at $-81^{\circ} \mathrm{C}$ until analysis. ${ }^{35}$

The concentrations of BRE in the blood and brain tissue were analysed by UPLC/MS. BRE concentrations were determined in the plasma and brain tissue samples obtained during the in vivo pharmacokinetic studies using a protein sediment extraction procedure. To extract BRE from the brain tissues, brain sample tissue (100 mg) from different parts of the rat brain was accurately weighed. Normal saline (1 $\mathrm{mL}$ ) was added to the tube and homogenized using a science TZ-192 Tissue Homogenizer at 25,000 rpm for 1 min. The brain tissue homogenate was centrifuged at $4000 \mathrm{rpm}$ for $15 \mathrm{~min}$ at $4^{\circ} \mathrm{C}$. A plasma aliquot $(100 \mu \mathrm{L})$ was spiked with $10 \mu \mathrm{L}$ of the methanolic IS solution (telmisartan, $175 \mathrm{ng} / \mathrm{mL}){ }^{36}$ Then, $290 \mu \mathrm{L}$ of methanol was added to the centrifuge tube, mixed by vortexing $(3 \mathrm{~min})$ and centrifuged at $15,000 \mathrm{r} / \mathrm{min}$ for $10 \mathrm{~min}$ to precipitate the protein content and extract the drug and the IS. BRE in the plasma and brain tissue samples was assayed using an $A B$ SCIEX Triple Quad ${ }^{\mathrm{TM}}$ API 5500 (AB Sciex, Framingham, MA) liquid chromatography-tandem mass spectrometry (LC/MS/MS) system. The chromatography column was a Welch XB-C18 $(3.0 \times 50 \mathrm{~mm}, 3 \mu \mathrm{m} ; \mathrm{MS} / \mathrm{MS})$. The mobile phase consisting of a $20 \mathrm{mmol} / \mathrm{L}$ ammonium acetate solution in water and acetonitrile was delivered to the MS at a flow rate of $0.7 \mathrm{~mL} / \mathrm{min}$ according to the following time gradient elution program: a linear gradient was applied by varying the proportion of acetonitrile from 15 to $70 \%$ in the first $1 \mathrm{~min}$; then, within $3 \mathrm{~min}$, the percentage of acetonitrile was restored to $70 \%$; subsequently, a linear gradient was applied by varying the proportion of acetonitrile from 70 to $15 \%$ from 3 to $3.1 \mathrm{~min}$ and maintained until the end of the run (5 min).

\section{Pharmacokinetic Analysis and Brain Targeting Efficiency Evaluation}

The corresponding main pharmacokinetic parameters were calculated by a noncompartmental pharmacokinetic analysis employing DAS version 3.0 software (Chinese Pharmacological Association). The absolute bioavailability of BRE after intranasal administration of BRE-NG was calculated by using the following equation (1):

$$
\mathrm{F} \alpha=\frac{\left(\mathrm{AUC}_{\text {in }} / \mathrm{D}_{\text {in }}\right)}{\left(\mathrm{AUC}_{\mathrm{iv}} / \mathrm{D}_{\mathrm{iv}}\right)}
$$

where $\mathrm{AUC}_{\mathrm{iv}}$ is the area under the plasma concentration-time profile from $\mathrm{t}=0$ to $8 \mathrm{~h}$ following intravenous administration 
of the BRE-NP nanosuspensions, $\mathrm{AUC}_{\text {in }}$ is the area under the plasma concentration-time profile from $\mathrm{t}=0$ to $8 \mathrm{~h}$ following intranasal administration of BRE-NG, and $\mathrm{D}_{\text {in }}$ and $\mathrm{D}_{\mathrm{iv}}$ represent the drug dose (mg) administered via intranasal and intravenous injection, respectively. $\mathrm{F}_{\alpha}$ represents the absolute bioavailability of BRE after intranasal administration of BRE-NG.

To evaluate the brain targeting efficiency of BRE-NG via intranasal administration, the drug targeting efficiency (DTE\%) was calculated by using the following equation (2), and the nose-to-brain direct transport percentage (DTP $\%$ ) was calculated by using the following equation (3), which assesses the drug fraction transported via the olfactory or trigeminal pathway.

$$
\begin{gathered}
\operatorname{DTE}(\%)=\frac{\left(\mathrm{AUC}_{\text {brain }} / \mathrm{AUC}_{\text {plasma }}\right) \mathrm{IN}}{\left(\mathrm{AUC} \mathrm{brain}_{\text {bra }} / \mathrm{AUC}_{\text {plasma }}\right) \mathrm{IV}} \times 100 \\
\operatorname{DTP}(\%)=\frac{\mathrm{AUC}_{\text {brainIN }}-\left[\frac{\mathrm{AUC}_{\text {brainIV }}}{\mathrm{AUC}_{\text {plasamalV }}} \times \mathrm{AUC}_{\text {plasmaIN }}\right]}{\mathrm{AUC}_{\text {brainIN }}} \\
\times 100
\end{gathered}
$$

where $\left(\mathrm{AUC}_{\text {brain }}\right)_{\mathrm{IV}}$ and $\left(\mathrm{AUC}_{\mathrm{brain}}\right)_{\mathrm{IN}}$ are the area under the brain concentration-time profile of the BRE-NP suspensions and BRE-NG from $\mathrm{t}=0$ to $8 \mathrm{~h}$ after administration, respectively. $\left(\mathrm{AUC}_{\text {plasma }}\right)_{\mathrm{IV}}$ and $\left(\mathrm{AUC}_{\text {plasma }}\right)_{\mathrm{IN}}$ represent the area under the plasma concentration-time profile of the BRE-NP nanosuspensions and BRE-NG from $\mathrm{t}=0$ to 8 $\mathrm{h}$ after administration, respectively. A DTE (\%) higher than $100 \%$ ensured preferential drug transport to the brain following intranasal administration compared to intravenous administration. ${ }^{37}$ The value of DTP (\%) can range from $-\infty$ to $100 \%$. Generally, positive values of the DTP (\%) indicate more efficient drug delivery to the brain following intranasal administration. Negative values of DTP (\%) indicate more efficient brain targeting via an intravenous administration route. ${ }^{38}$

\section{Data Analysis}

The results are presented as mean \pm standard deviation. The $t$ test was used in the statistical analyses, which was performed using SPSS software. $\mathrm{p}<0.05$ and $\mathrm{p}<0.01$ were considered statistically significant.

\section{Histopathology}

To investigate the effect of BRE-NG application on induced ischemia stroke in rats, in vitro histopathological characterization was performed. The rats were randomly divided into six groups (18 rats in each group): a high-dose group (BRE-
NG was intranasally administered at a dose of $20 \mathrm{mg} / \mathrm{kg}$ ), a medium-dose group (BRE-NG was intranasally administered at a dose of $10 \mathrm{mg} / \mathrm{kg}$ ), a low-dose group (BRE-NG was intranasally administered at a dose of $5 \mathrm{mg} / \mathrm{kg}$ ), a cerebral ischemic model with nimodipine treatment group (positive group), a sham group (negative group) and a cerebral ischemic model group (model group). The model of global cerebral ischemia was generated through bilateral common carotid artery occlusion (BCCAO). ${ }^{39}$ The rats were sacrificed after the experimental period, after which their whole brains were removed. The brains were fixed in $10 \%$ neutral buffered formalin solution. The slides were then dehydrated by successive dilutions of ethanol and finally washed in xylene three times. The sections were cut $(5 \mu \mathrm{m})$ using a microtome and stained with haematoxylin-eosin (H\&E). The section thicknesses were obtained by a histopathological examination under a LEICADM LB binocular microscope.

\section{Results and Discussion Characterization of BRE-NP}

BRE-NS stabilized by only $10 \%$ Tween- $80(\mathrm{w} / \mathrm{w}$, relative to drug) with a particle size of $527 \pm 1 \mathrm{~nm}$ and an absolute zeta potential value higher than $20 \mathrm{mV}$ were successfully prepared by homogenization technology. An absolute Zeta potential value higher than $20 \mathrm{mV}$ has been reported to be sufficient to stabilize nanosuspensions. The zeta potential was $-46.4 \pm 7.87 \mathrm{mV}$, which indicated that BRE-NS was comparatively stable. The zeta-potential results of the BRE-NP are shown in Figure 2A.

The surface morphologies of the raw BRE and BRENP are shown in Figure 2. The raw BRE particles were irregularly shaped and nonuniformly sized. The BRE-NP particles were spherical with smooth edges and homogenous sizes. In brief, the investigated morphologies of the BRE-NP and the raw BRE were different. According to the literature reports, if the inlet gas flow rates and feed temperature are not adjusted properly during spray-drying, it would cause fused or donut-shaped particles to be formed. However, fused or donut-shaped particles did not appear, which demonstrated that the process was carried out under optimized conditions. ${ }^{40}$

TEM was used to observe the morphology of the BRENP, as shown in Figure 2F. According to the TEM results, the BRE-NP had a rod shape, which might be attributed to the process of high-pressure homogenization. During this process, the drug suspension passes the narrow orifice of 

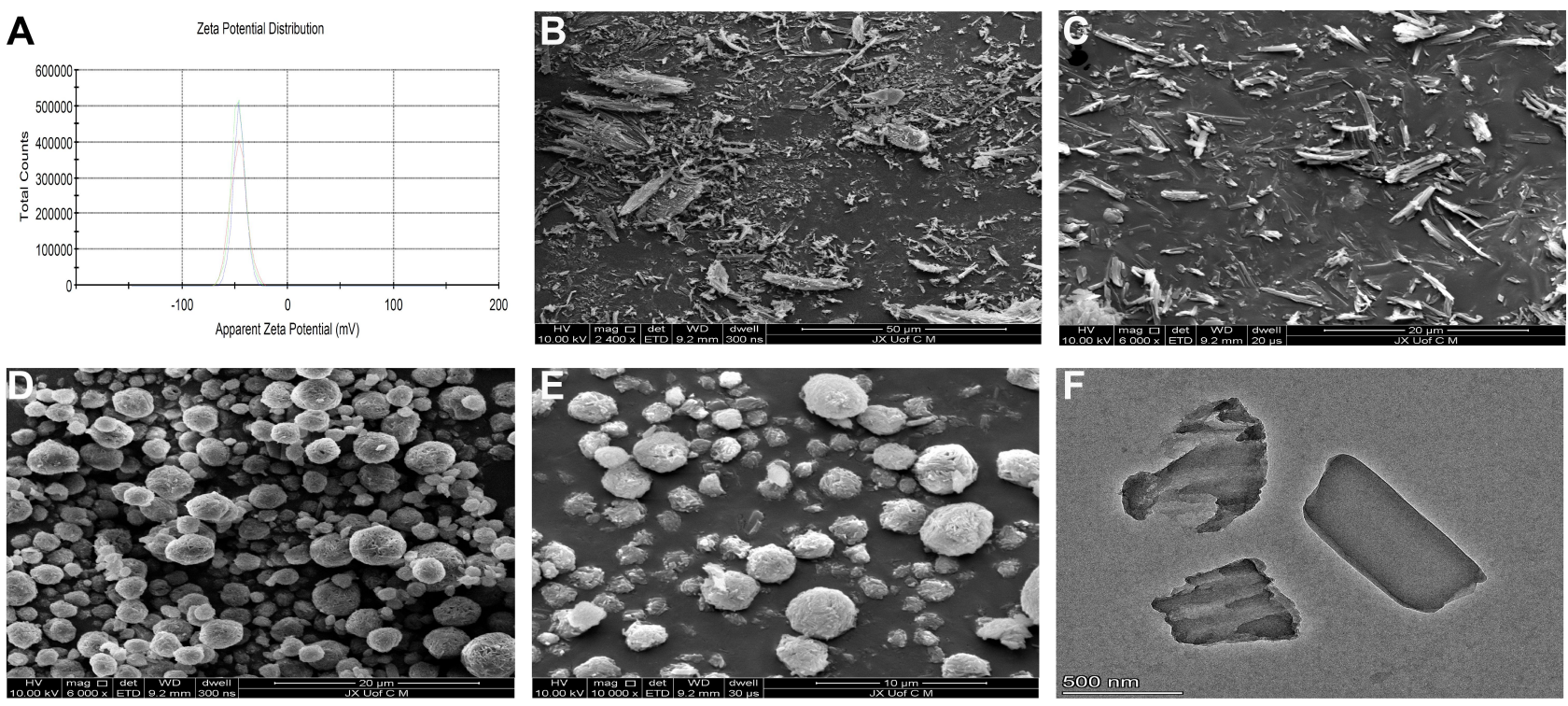

Figure 2 (A) The zeta-potential results of the BRE-NP, SEM images of $(B)$ the raw BRE $(\times 2400),($ C) the raw BRE $(\times 6000)$, (D) BRE-NP $(\times 6000)$, $($ E) BRE-NP $(\times 10,000)$, and (F) TEM images of the BRE-NP.

the homogenizer at a high speed. The rod shape is formed due to cavitation, high shear forces, and collision of the particles with each other. ${ }^{41}$

Crystallinity is one of the most important factors affecting the stability, solubility and dissolution rate of drugs. The internal crystalline structure of BRE, the physical mixtures and the nanosuspensions produced using the homogenization technology were investigated by PXRD. The PXRD patterns of BRE-NP, raw BRE, mannitol, and the physical mixture of raw BRE and mannitol are shown in Figure 3. The typical crystalline peaks of raw BRE at $2 \theta$ of $14.3^{\circ}, 16.0^{\circ}, 25.9^{\circ}, 26.8^{\circ}$ were detected in the PXRD patterns, indicating its crystalline structure. Typical crystalline peaks of mannitol at $2 \theta$ values of $17.2^{\circ}, 18.7^{\circ}$, $20.4^{\circ}$, and $21.1^{\circ}$ were observed. These results appeared to be consistent with several previous reports. ${ }^{18,42}$ In addition, the typical crystalline peaks of raw BRE in the physical mixtures of raw BRE and mannitol and BRE$\mathrm{NP}$ indicated that the homogenization process did not affect the crystalline structure of BRE.

DSC analysis was performed to determine the polymorphic state and polymorphic nature of BRE. The DSC thermograms of raw BRE, BRE-NP, mannitol, and the physical mixture of raw BRE and mannitol are shown in Figure 4. Raw BRE exhibited a characteristic endothermic melting peak at $203.5^{\circ} \mathrm{C}$. Mannitol exhibited a characteristic exothermic melting peak at $175^{\circ} \mathrm{C}$. The endothermic melting peak of BRE-NP shifted to $188.5^{\circ} \mathrm{C}$, and the exothermic melting peak shifted to $165.4^{\circ} \mathrm{C}$, but the enthalpy decreased.
This indicated that neither the stabilizer modification nor the applied physical treatment remarkably affected the endothermic behaviour of BRE.

\section{Gelatine Property Evaluation of the in situ Gel}

Deacetylated gellan gum (DGG) is an anionic polysaccharide secreted by Pseudomonas elodea. Nasal fluids with abundant cations, especially $\mathrm{Ca}^{2+}$, converted the DGG solutions to gels. Due to its adhesive nature, the in situ gel could lengthen the mucosal residence time, sustaining their residency in the nasal cavity and then enhance the bioavailability of intranasal administration. ${ }^{15}$ Deacetylated gellan gum is commercially available as Gelrite ${ }^{\mathrm{TM}}$ or Kelcogel ${ }^{\mathrm{TM}}$ and is approved in the USA and EU as a gelling, stabilizing and suspending agent in food products. Therefore, deacetylated gellan gum is safe for pharmaceutical use. ${ }^{7,8}$ The BRE nanosuspension-based in situ gel was prepared in three steps. The first step was the preparation of BRE-NS, the second step was the preparation of BRE-NP, and the third step was in situ gelling fabrication and the mixture of the BRE-NP with the in situ gelling polymer phase. ${ }^{14}$

The DGG solutions can be transformed to gels upon contact of the gels with nasal fluid after intranasal administration. Therefore, determination of the critical ionic concentration (CIC) of deacetylated gellan gum is of great significance to evaluate the gel formation. Thus, the minimum amount of simulated nasal fluid required for the 

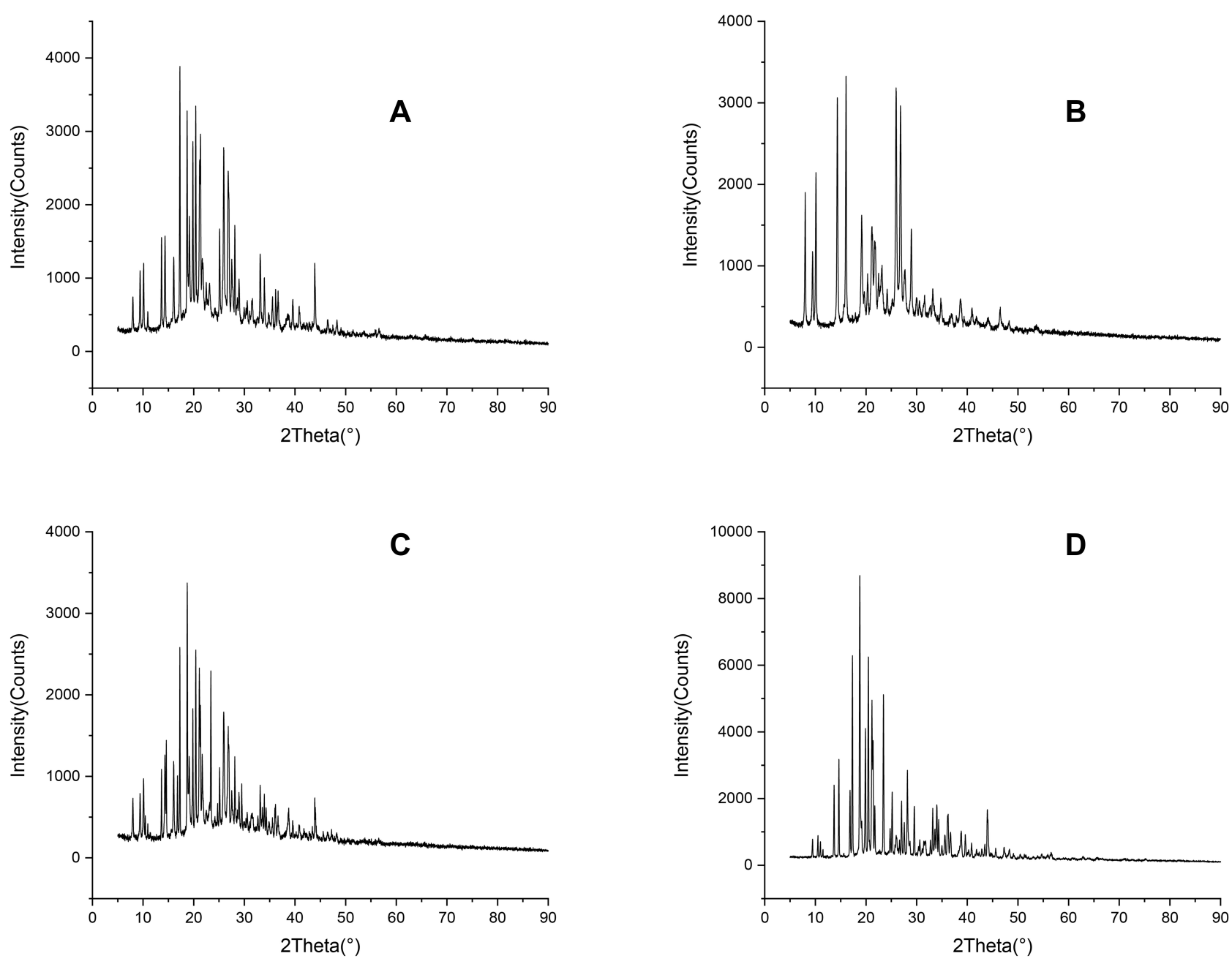

Figure 3 PXRD patterns of (A) the BRE-NP, (B) raw BRE, (C) mannitol, (D) the physical mixture of raw BRE and mannitol.

sol-gel transition was considered the best batch. ${ }^{43}$ The critical ionic concentration results are shown in Table 1. DGG solutions of $0.3 \%$ or below could not be converted from the solution to a gel. DGG solutions of $0.5 \%$ or below required an unrealistic amount of ANF for the solution-to-gel transition to occur. DGG solutions of $0.5 \%$ and $0.6 \%$ only needed a small amount of ANF to rapidly transform from solutions to gels. The DGG solution of $0.6 \%$ could rapidly transform to a gel without any ANF. Therefore, the DGG solution of $0.5 \%$ was considered the optimal choice. Viscosity is also an indicator of intranasal administration. High viscosity could prolong the residence time of the drug in the nasal mucous membranes and significantly increase the drug absorption. The viscosity results are shown in Table 2 . The appropriate viscosity for intranasal administration should be approximately 5.0 $\mathrm{Pa} \bullet \mathrm{s}$. Viscosities higher than $5.0 \mathrm{~Pa} \cdot \mathrm{s}$ can cause shortness of breath in patients. Viscosities below 5.0 Pa•s can cause in situ gel flow from the nasal cavity. ${ }^{44}$ Therefore, the optimal DGG:ANF ratio was 10:5.

During the solution-gel phase transition, the volume may increase due to expansion of the gel, causing physical discomfort in the nasal cavity. Therefore, it is necessary to investigate the expansion coefficient $(\mathrm{S} \%)$ of the in situ gels. When the expansion coefficient was only approximately $5 \%$, it may not cause any discomfort in patients. ${ }^{45}$ The results of $\mathrm{S} \%$ of different concentrations of DGG are shown in Figure 5A. The smallest $\mathrm{S} \%$ was obtained for the DGG solution of $0.5 \%$, which was $1.46 \%$. The results revealed that no obvious volume expansion was observed. Thus, when the solution was applied to the nasal cavity, there was no significant discomfort in patients due to the process of solution-gel phase transition.

To ensure good mucoadhesive behaviour, all in situ gels were capable of hydrating and retaining water. ${ }^{46} \mathrm{~A}$ high water-holding capacity can ensure a certain humidity in the 


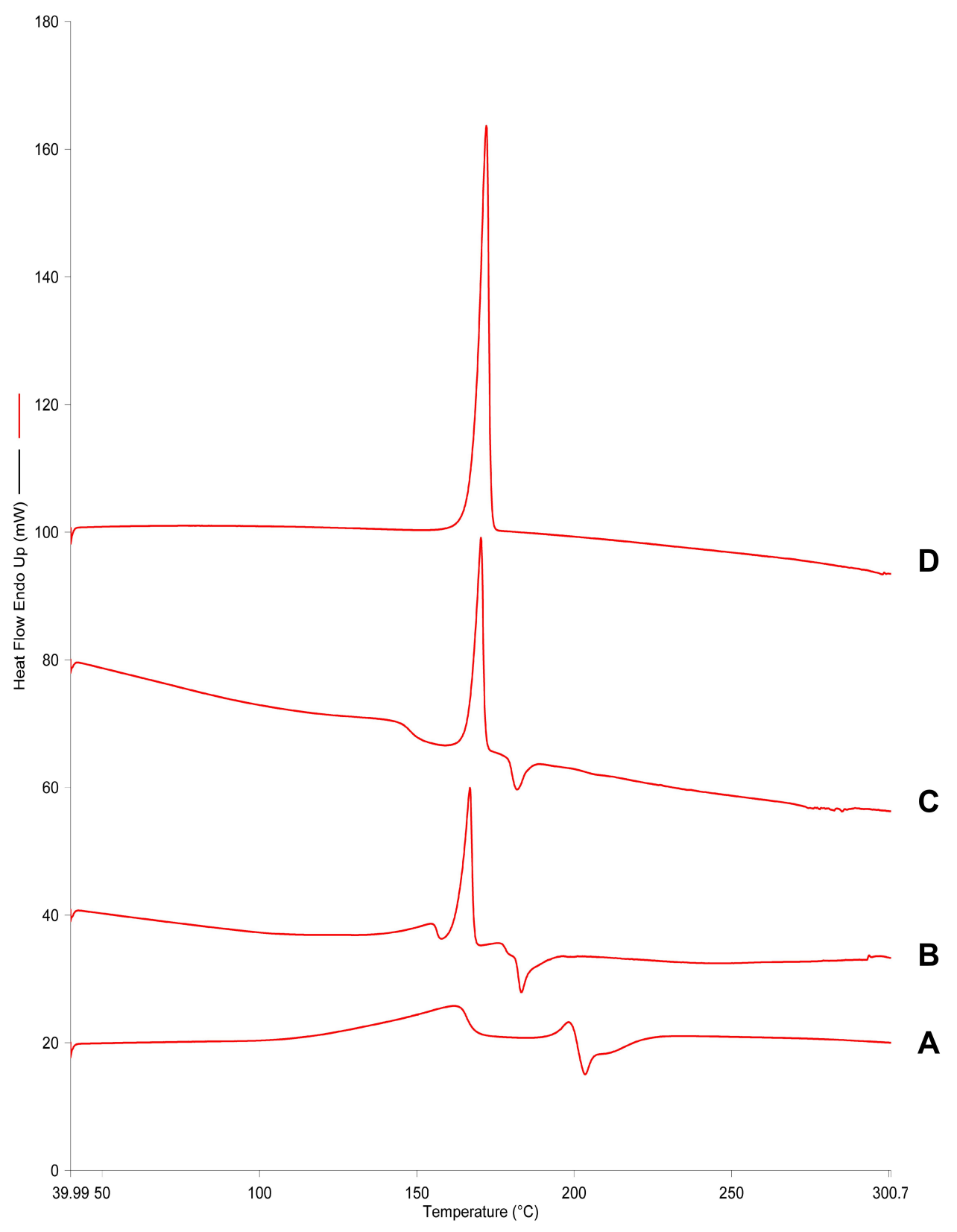

Figure 4 DSC thermograms of (A) raw BRE, (B) BRE-NP, (C) the physical mixture of raw BRE and mannitol, and (D) mannitol.

nasal mucosa, which contributes to the absorption of the drug through the nasal mucosa. The results of the water-holding capacity of different concentrations of DGG are shown in Figure 5B. All the samples had favourable water-holding capacity except the DGG solution of $0.2 \%$. The results indicated good water-holding capacity because the threedimensional network of the gel structure can effectively capture and immobilize water. Therefore, a DGG concentration of $0.5 \%$ showed a higher water-holding capacity than a concentration of $0.2 \%$.

\section{Rheological Evaluation}

Rheological measurements were performed using the Physica MCR101 rheometer system (Anton Paar GmbH, Austria) with a cone-plate sensor (PP50-1) in the OSR model with a stress sweep rate between 3 and $500 \mathrm{~Pa}$ and a temperature of $30^{\circ} \mathrm{C}$ at a constant frequency of $1 \mathrm{~Hz}$. G' corresponds to the elastic (storage) and G" to the viscous (loss) modulus. The frequency sweep curves of the BRE-NG without ANF and BRE-NG mixed with ANF are shown in Figure 6. As depicted in Figure 6A and B, the 
Table I Gelation Property of DGG with Artificial Nose Fluid (ANF)

\begin{tabular}{|c|c|c|c|c|c|c|c|c|}
\hline \multirow[t]{2}{*}{ The Concentration of DGG (\%) } & \multicolumn{8}{|c|}{ The Ratio of DGG:ANF } \\
\hline & $10: 0.5$ & $10: 1$ & $10: 1.5$ & $10: 2$ & $10: 2.5$ & $10: 3$ & $10: 4$ & $10: 5$ \\
\hline 0.2 & - & - & - & - & - & - & - & - \\
\hline 0.3 & - & \pm & \pm & \pm & \pm & \pm & \pm & + \\
\hline 0.4 & - & \pm & \pm & \pm & \pm & \pm & + & + \\
\hline 0.5 & - & + & + & + & + & + & + & + \\
\hline 0.6 & - & + & + & + & + & + & + & + \\
\hline 0.7 & + & + & + & + & + & + & + & + \\
\hline 0.8 & + & + & + & + & + & + & + & + \\
\hline 0.9 & + & + & + & + & + & + & + & + \\
\hline 1.0 & + & + & + & + & + & + & + & + \\
\hline
\end{tabular}

Abbreviation: ANF, artificial nasal fluid.

Table 2 Viscosity of 0.5\% Deacetylated Gellan Gum in situ Gel After Mixing with Simulated Nasal Fluid in Different Proportions

\begin{tabular}{|l|l|}
\hline The Ratio of DGG:ANF & Viscosity (Pa-s) \\
\hline $10: 0.5$ & 0.015 \\
$10: 1$ & 3.980 \\
$10: 1.5$ & 4.514 \\
$10: 2$ & 4.615 \\
$10: 2.5$ & 4.657 \\
$10: 3$ & 4.659 \\
$10: 4$ & 4.747 \\
$10: 5$ & 4.819 \\
\hline
\end{tabular}

Abbreviation: ANF, artificial nasal fluid.

elastic (storage) modulus did not intersect with the viscous (loss) modulus of the BRE-NG without ANF $\left(\mathrm{G}^{\prime}<\mathrm{G}^{\prime \prime}\right)$, which indicated a viscous fluid character and no gel formation. The elastic (storage) modulus intersected with the viscous (loss) modulus of the BRE-NG mixed with ANF

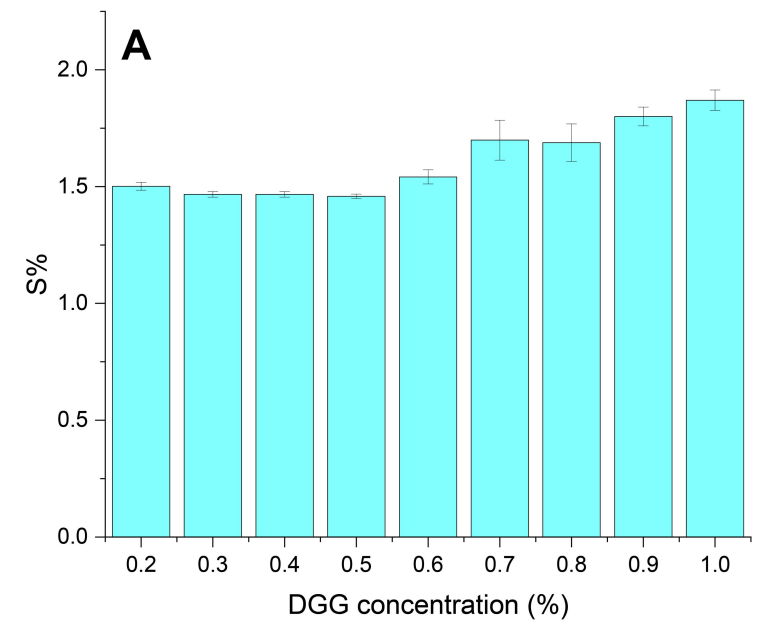

(G'> G'), which indicated elastic characteristics and successful gel formation. As depicted in Figure $6 \mathrm{C}$ and D, the shear stress was proportional to the shearing rate, and it was concluded that the BRE-NG without ANF was a Newtonian fluid. The viscosity decreased due to the increase in the shearing rate, and it was concluded that the BRE-NG mixed with ANF showed non-Newtonian and pseudoplastic behaviour. These characteristics indicated that the solution-gel phase transition occurred when BRE-NG came in contact with the nasal fluids. It was assumed that the in situ gel significantly increased the retention time at the administration site, as it showed good spreadability and bioadhesion performance.

\section{In vitro Release Study}

The in vitro release study was carried out by using a semipermeable membrane (Spectra/Por 1 membrane,

Figure 5 (A) The S\% of different concentration of DGG. (B) the water-holding capacity of different concentration of DGG $(n=3)$. Abbreviations: DGG, deacetylated gellan gum; $S \%$, the expansion coefficient. 

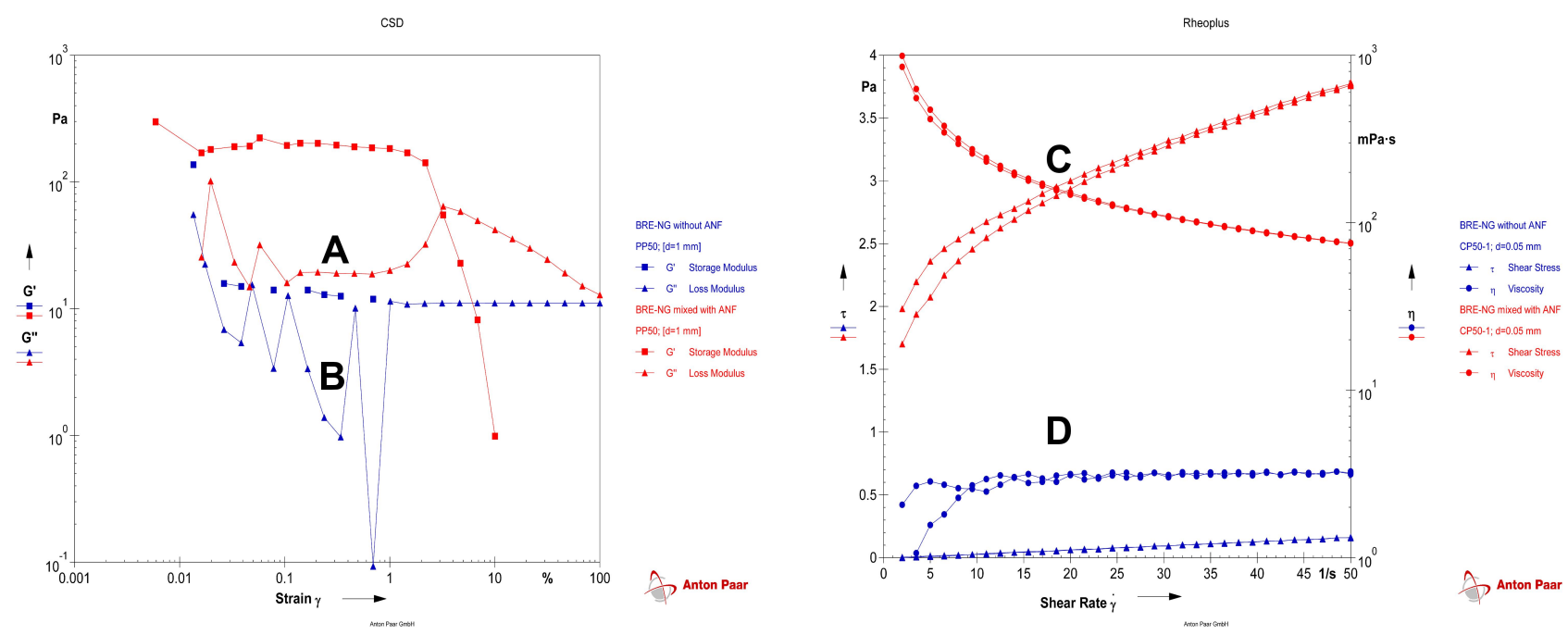

Figure 6 The viscoelasticity of (A) the BRE-NG mixed with ANF, (B) the BRE-NG without ANF and (C) the thixotropy of BRE-NG mixed with ANF, (D) the BRE-NG without ANF.

Abbreviation: ANF, artificial nasal fluid.

MWCO: $8000 \sim 14,000$ ) as a diffusional barrier to simulate the process of drug absorption through the nasal mucous membrane in vitro using Franz diffusion cells. This in vitro release study was applied to evaluate the permeability of the drug released from the in situ gel for intranasal delivery. The in vitro cumulative drug release is shown in Figure 7A. The results showed that BRE-NG had a slower release than BRE-NP. BRE-NG exhibited slower release characteristics, which was significantly different from the in vitro release behaviour of BRE-NP. The release data of BRE-NP and BRE-NG were kinetically analysed by three different mathematical models, which was used to better understand the differences between the in vitro release behaviours of BRE-NP and BRE-NG. The results are shown in Table 3. Considering the $\mathrm{R}^{2}$ values, the zero-order model was found to fit the BRE-NP $\left(\mathrm{R}^{2}=0.990\right)$, indicating a constant drug transport rate of the BRE-NP. The Higuchi model was found to fit the BRE-NG $\left(\mathrm{R}^{2}=0.942\right)$, indicating that the drug release was matrix diffusion-controlled as a function of time. ${ }^{14}$ The incorporation of BRE-NP in the in situ gel resulted in a noticeable increase in the retention time and reduction in the drug leakage from the nasal cavity.
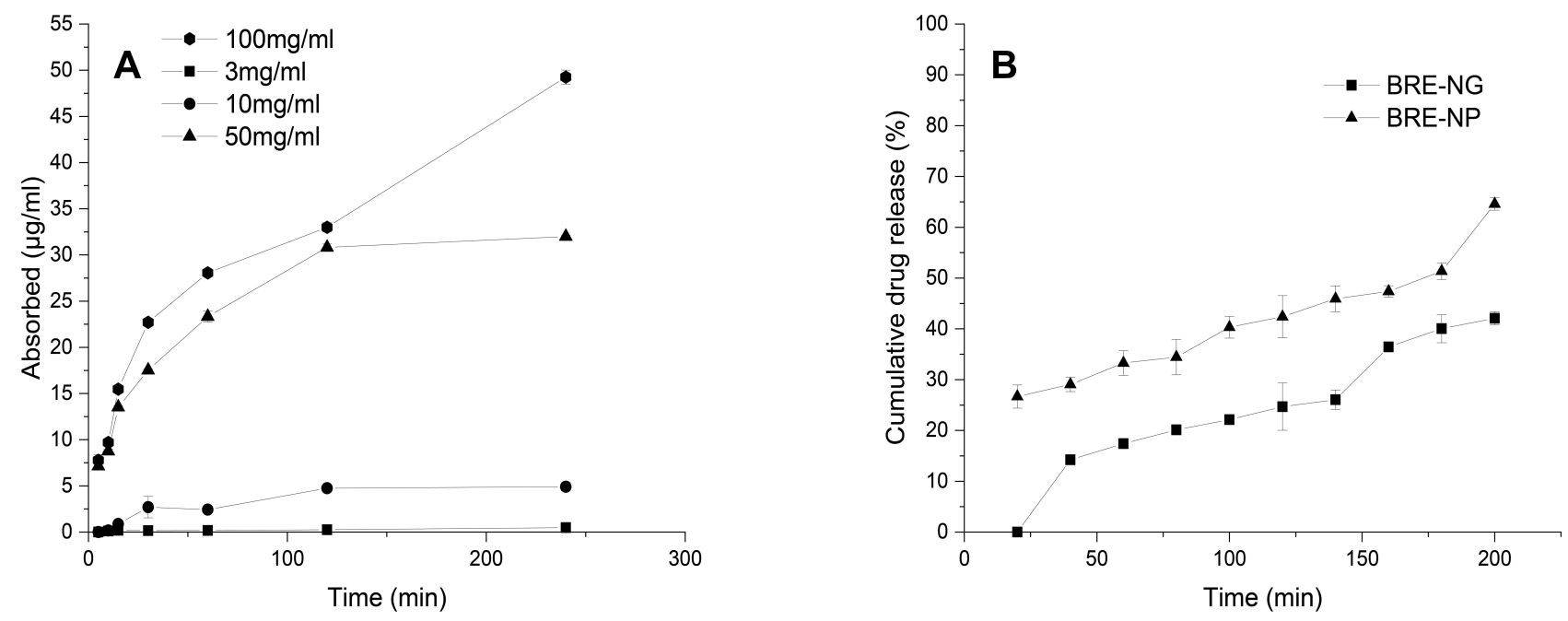

Figure 7 (A) Profiles of cumulative drug release of BRE-NG and BRE-NP nanosuspensions in vitro $(n=3)$ and $(B)$ nasal absorption of BRE at different concentration of BRENG perfusion liquid $(n=3)$.

Abbreviations: BRE, breviscapine; BRE-NP, BRE nanosuspensions powders; BRE-NG, BRE nanosuspensions in-situ gelling system. 
Table 4 Nasal Absorption of BRE at Different Concentration of BRE-NG Perfusion Liquid $(n=3)$

\begin{tabular}{|l|l|l|l|l|}
\hline Time (min) & $\mathbf{3 m g} / \mathbf{m L}$ & $\mathbf{1 0} \mathbf{m g} / \mathbf{m L}$ & $\mathbf{5 0 m g / m L}$ & $\mathbf{1 0 0} \mathbf{m g} / \mathbf{m L}$ \\
\hline 5 & $0.00 \pm 0.00$ & $0.00 \pm 0.00$ & $7.14 \pm 0.42$ & $7.77 \pm 0.63$ \\
10 & $0.11 \pm 0.04$ & $0.17 \pm 0.05$ & $8.77 \pm 0.17$ & $9.70 \pm 0.33$ \\
15 & $0.19 \pm 0.13$ & $0.88 \pm 0.20$ & $13.53 \pm 0.13$ & $15.46 \pm 0.35$ \\
30 & $0.16 \pm 0.09$ & $2.70 \pm 1.15$ & $17.52 \pm 0.11$ & $22.70 \pm 0.29$ \\
60 & $0.17 \pm 0.08$ & $2.42 \pm 0.11$ & $23.32 \pm 0.59$ & $28.05 \pm 0.35$ \\
120 & $0.24 \pm 0.16$ & $4.75 \pm 0.22$ & $30.82 \pm 0.37$ & $32.99 \pm 0.50$ \\
240 & $0.48 \pm 0.02$ & $4.90 \pm 0.44$ & $32.00 \pm 0.15$ & $49.25 \pm 0.76$ \\
\hline
\end{tabular}

Table 3 Fitted Model for in vitro Release of Franz Diffusion Cells Model

\begin{tabular}{|l|l|l|l|}
\hline & Model & Fitting Equation & $\mathbf{R}^{\mathbf{2}}$ \\
\hline BRE-NP & Zero-order equation & $\mathrm{Q}=0.1558 \mathrm{t}+23.402$ & 0.99 \\
& First-order equation & $\mathrm{Q}=100 \cdot\left[\mathrm{I}-\mathrm{e}^{-0.015 \cdot(\mathrm{t}-55.764)}\right]$ & 0.689 \\
& Higuchi equation & $\mathrm{Q}=3.042 \mathrm{t}^{1 / 2}+7.352$ & 0.888 \\
\hline BRE-NG & Zero-order equation & $\mathrm{Q}=0.2045 \mathrm{t}+1.8239$ & 0.935 \\
& First-order equation & $\mathrm{Q}=100 \cdot\left[\mathrm{I}-\mathrm{e}^{-0.002 \cdot(\mathrm{t}-127.120)}\right]$ & 0.937 \\
& Higuchi equation & $\mathrm{Q}=3.923 \mathrm{t}^{1 / 2}-15.099$ & 0.942 \\
\hline
\end{tabular}

Abbreviations: BRE, breviscapine; BRE-NP, BRE nanosuspensions powders; BRE-NG, BRE nanosuspensions in-situ gelling system; Q, cumulative release of BRE (\%);t, time (hour); $t^{1 / 2}$, the half power of $t$; e, mathematical constant.

\section{In situ Nasal Absorption of BRE in Rats}

The in situ nasal perfusion study is the most commonly used method to examine the drug absorption from the nasal mucosa of rats, and it is widely used to assess the nasal mucosal absorption of drugs. ${ }^{47}$ The brain uptake following intranasal perfusion is mainly determined by the drug concentration and the perfusion time. The highest uptake was observed at $100 \mathrm{mg} / \mathrm{mL}$ and $240 \mathrm{~min}$ (Table 4 and Figure 7B). At lower concentrations of BRE in the solution, the drug adsorption was lower. The uptake concentration increased with increasing concentration of BRE. When the perfusion time was 120 min, the uptake of BRE showed little variation. This suggested that there was a saturation phenomenon in the intranasal absorption of BRE. ${ }^{33}$ This phenomenon could be explained by the fact that hydration between the drug solution and nasal mucosa reduced the effective lipoidal pathway on the membrane due to long contact times. ${ }^{48}$

\section{In vivo Pharmacokinetic and Brain Distribution Studies}

To evaluate the in vivo effectiveness of BRE-NG and its brain distribution after intranasal administration, the concentrations of BRE in plasma and various regions of brain tissue, ie, cerebrum, cerebellum and olfactory bulb, were determined after intravenous injection administration (IV) of the BRE-NP nanosuspensions and intranasal administration (IN) of BRE-NG $(20 \mathrm{mg} / \mathrm{kg})$. The mean BRE concentrations in plasma, cerebrum, cerebellum and olfactory bulb along with the remaining portion of the brain were analysed at predefined time points up to $8 \mathrm{~h}$ postdosing. The main pharmacokinetic parameters were estimated by a noncompartmental pharmacokinetic analysis. As shown in Figure 8 and Tables 5 and 6 , the $T_{\max }$ of the intranasal groups was $(0.167 \pm 0.000) \mathrm{h}$, indicating that BRE was easily and rapidly accessible in the systemic circulation after intranasal administration. The $\mathrm{t}_{1 / 2}(1.805$ $\pm 0.650) \mathrm{h}$ of the intranasal groups appeared to be 4.5 times longer than that of the intravenous groups. This indicated that the prolonged retention time in vivo was related to the adhesive property of the in situ gel. The AUC $_{(0-8 \mathrm{~h})}$ of the intranasal groups was $304.81 \pm 20.101$ $\mu \mathrm{g} / \mathrm{L} * \mathrm{~h}$, and the $\mathrm{AUC}_{(0-8 \mathrm{~h})}$ of the intravenous groups was $533.613 \pm 69.339 \mu \mathrm{g} / \mathrm{L} * \mathrm{~h}$, which indicated that the concentration of BRE in plasma was reduced due to the accumulation of BRE in other tissues after intranasal administration.

Compared with intravenous administration, the estimate absolute bioavailability of BRE after intranasal administration was $57.12 \%$. The absolute bioavailability of BRE after oral administration has been reported as $0.40 \pm 0.19 \%$, which 

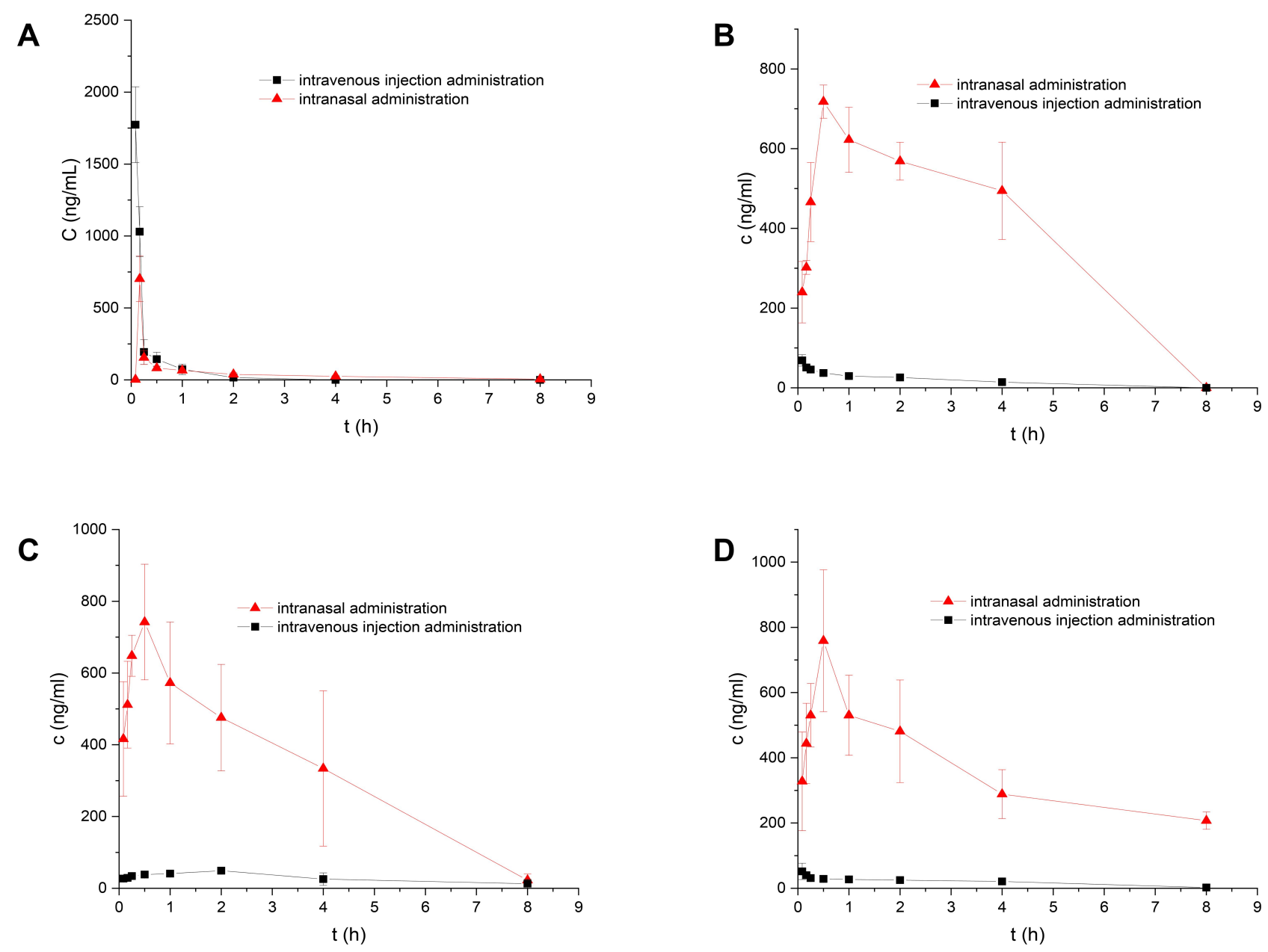

Figure 8 Concentration-time profiles of BRE up to $8 \mathrm{~h}$ post-dosing in (A) plasma, (B) cerebrum tissue, (C) cerebellum tissue and (D) olfactory bulb tissue following after intravenous injection administration (IV) of BRE-NP nanosuspensions and intranasal administration of BRE-NG at a dose of $20 \mathrm{mg} \cdot \mathrm{kg}^{-1}(\mathrm{n}=6$ ).

Abbreviations: BRE, breviscapine; BRE-NP, BRE nanosuspensions powders; BRE-NG, BRE nanosuspensions in-situ gelling system; $c$, concentration of breviscapine; $t$, time (hour).

indicates that BRE-NG notably enhanced the bioavailability of BRE in rats after intranasal administration. ${ }^{42}$ The DTE\% was calculated for BRE to assess its brain targeting ability. As shown in Tables 5 and 6, the DTE\% of the cerebrum, cerebellum and olfactory bulb was 4006, 1999 and 3290, respectively. A DTE (\%) higher than 100\% indicates preferential drug transport to the brain following intranasal administration compared to systemic administration. The DTP\% was calculated as shown in Tables 5 and 6 . The DTP\% of the cerebrum, cerebellum and olfactory bulb were $0.975,0.950$

Table 5 The Plasma Pharmacokinetic Parameters After Intravenous Administration of BRE-NP Suspensions and Intranasal Administration of BRE-NG at a Dose of $20 \mathrm{mg}^{\circ} \mathrm{kg}^{-1}($ Mean $\pm \mathrm{SD}, \mathrm{n}=6$ )

\begin{tabular}{|l|l|l|l|}
\hline Parameter & Unit & IV Administration & IN Administration \\
\hline $\mathrm{AUC}_{(0-8 \mathrm{~h})}$ & ug/L*h & $533.613 \pm 69.339$ & $304.8 \mathrm{I} \pm 20.10 \mathrm{I} * *$ \\
$\mathrm{MRT}_{(0-8 \mathrm{~h})}$ & $\mathrm{h}$ & $0.312 \pm 0.067$ & $1.836 \pm 0.375 * *$ \\
$\mathrm{t}_{\mathrm{I} / 2 \mathrm{z}}$ & $\mathrm{h}$ & $0.40 \mathrm{I} \pm 0.07 \mathrm{I}$ & $1.805 \pm 0.650 *$ \\
$\mathrm{~T}_{\max }$ & $\mathrm{h}$ & $0.083 \pm 0.000$ & $0.167 \pm 0.000 * *$ \\
$\mathrm{C}_{\max }$ & ug/L & $1773.333 \pm 263.88 \mathrm{I}$ & $158.885 \pm 22.600 * *$ \\
\hline
\end{tabular}

Notes: ${ }^{*} p<0.05$ vs intravenous injection administration of BRE-NP suspensions. ${ }^{* *} \mathrm{p}<0.01$ vs intravenous injection administration of BRE-NP suspensions.

Abbreviations: IV, intravenous injection; IN, intranasal; AUC, the area under the curve; MRT, the mean residence time; tI/2z, the distribution phase half-life; $\mathrm{T}_{\text {max }}$, the time of maximum concentration; $\mathrm{C}_{\max }$, the peak drug concentration. 
Table 6 Brain Regional Pharmacokinetic Parameters of After Intravenous Administration of BRE-NP Suspensions and Intranasal Administration of BRE-NG at a Dose of $20 \mathrm{mg}^{\circ} \mathrm{kg}^{-1}($ Mean $\pm \mathrm{SD}, \mathrm{n}=6$ )

\begin{tabular}{|c|c|c|c|c|}
\hline Route & Parameter(Unit) & Cerebrum & Cerebellum & Olfactory Bulb \\
\hline IV & $\begin{array}{l}\mathrm{AUC}_{(0-8 \mathrm{~h})}(\mathrm{ug} / \mathrm{L} * \mathrm{~h}) \\
\mathrm{MRT}_{(0-8 \mathrm{~h})}(\mathrm{h}) \\
\mathrm{t}_{/ / 2 \mathrm{z}}(\mathrm{h}) \\
\mathrm{T}_{\max }(\mathrm{h}) \\
\mathrm{C}_{\max }(\mathrm{ug} / \mathrm{L})\end{array}$ & $\begin{array}{l}139.603 \pm 33.69 \mid \\
1.987 \pm 0.229 \\
1.937 \pm 1.506 \\
0.083 \pm 0.000 \\
68.7 \pm 14.204\end{array}$ & $\begin{array}{l}232.376 \pm 73.769 \\
2.807 \pm 0.895 \\
4.268 \pm 3.662 \\
2.000 \pm 0.000 \\
48.967 \pm 2.663\end{array}$ & $\begin{array}{l}151.259 \pm 3.570 \\
2.807 \pm 0.895 \\
1.822 \pm 0.420 \\
0.083 \pm 0.000 \\
51.800 \pm 25.039\end{array}$ \\
\hline IN & $\begin{array}{l}A \cup C_{(0-8 h)}(\text { ug/L*h) } \\
M R T_{(0-8 h)}(h) \\
t_{1 / 2 z}(h) \\
T_{\max }(h) \\
C_{\max }(\text { ug/L) }\end{array}$ & $\begin{array}{l}3194.833 \pm 501.745^{* *} \\
2.574 \pm 0.127^{*} \\
0.345 \pm 0.003 \\
0.500 \pm 0.000^{* *} \\
718 \pm 41.58 \mathrm{I}^{* *}\end{array}$ & $\begin{array}{l}2653.140 \pm 942.883^{*} \\
2.354 \pm 0.345 \\
2.076 \pm 0.613 \\
2.000 \pm 0.000^{* *} \\
750.333 \pm 149.82 I^{* *}\end{array}$ & $\begin{array}{l}2837.736 \pm 479.318^{* *} \\
3.125 \pm 0.359 \\
4.439 \pm 0.533^{* *} \\
0.500 \pm 0.000^{* *} \\
759.000 \pm 217.470^{* *}\end{array}$ \\
\hline
\end{tabular}

Notes: ${ }^{*} p<0.05$ vs intravenous injection administration of BRE-NP suspensions. ${ }^{*} \mathrm{p}<0.0 \mathrm{I}$ vs intravenous injection administration of BRE-NP suspensions. Abbreviations: IV, intravenous injection administration; IN, intranasal administration; AUC, the area under the curve; MRT, the mean residence time; tI/2z, the distribution phase half-life; $T_{\max }$, the time of maximum concentration; $C_{\max }$, the peak drug concentration.

and 0.970 , respectively. Positive values of the DTP $(\%)$ indicate a significant contribution of direct routes to the overall brain delivery. As displayed in Figure 9, this facilitated the adsorption of BRE into the brain because the sustained BRE concentration in the olfactory bulbs generated a concentration gradient difference. It was thought that there were two possible pathways of intranasal absorption to the brain: an indirect route, by which the drug is absorbed into the systemic circulation and entered into the brain through the $\mathrm{BBB}$, and a direct route, by which the drug is absorbed and transported to the brain through a neuronal pathway, such as olfactory or trigeminal nerves, and the other pathways involving the CSF, vasculature or lymphatic system. ${ }^{36}$ The results revealed the significant role of the direct pathway in the brain delivery of BRE-NG after intranasal administration. Generally, passage through olfactory and trigeminal nerves is the major and direct route of drug absorption from the nasal cavity to the brain. The olfactory neuronal path is the main pathway, as it is a direct connection from the nasal cavity to the olfactory bulb of the brain by crossing the cribriform plate. The drug is transmitted in three major ways: passive diffusion, paracellular movement or endocytosis by neuronal cells. ${ }^{49}$ On the other hand, a connection of the nasal cavity with the cerebrum and pons region of the brain and to the frontal cortex and olfactory bulb is established to a smaller extent by the trigeminal nerve. ${ }^{50}$ Thus, we concluded that the most likely mechanism of BRE direct access to the brain was involved in the fast release of drug molecules from the in situ gel matrix. Then, the drug molecules were easily absorbed on the olfactory bulb in the subarachnoid space, and the subsequent absorption of the drug molecules was related to the transfer from the olfactory bulb to the brain.
Intravenous injection administration

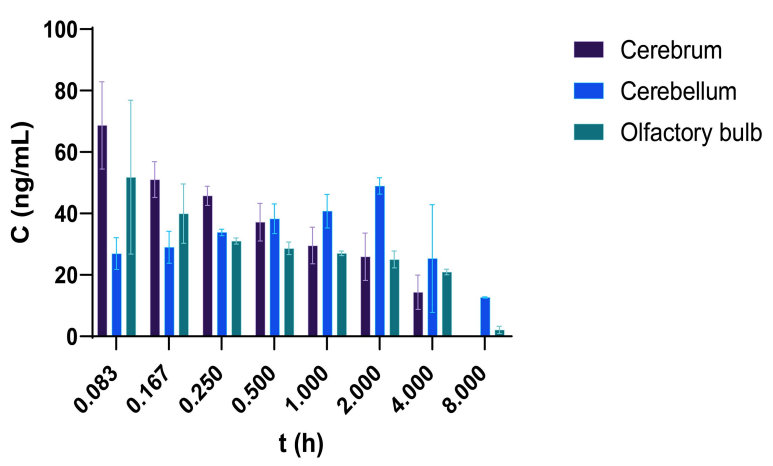

Intranasal administration

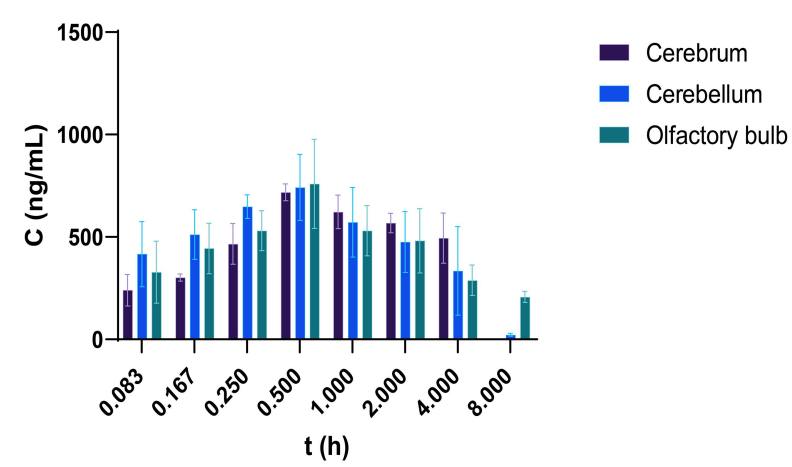

Figure 9 BRE concentrations in plasma and different brain regions (cerebrum, cerebellum and olfactory bulb) after intravenous administration of BRE-NP nanosuspensions and intranasal administration of BRE-NG at a dose of $20 \mathrm{mg}^{\circ} \mathrm{kg}^{-1}(\mathrm{n}=6)$.

Abbreviations: BRE, breviscapine; BRE-NP, BRE nanosuspensions powders; BRE-NG, BRE nanosuspensions in-situ gelling system; c, concentration of breviscapine; t, time (hour). 

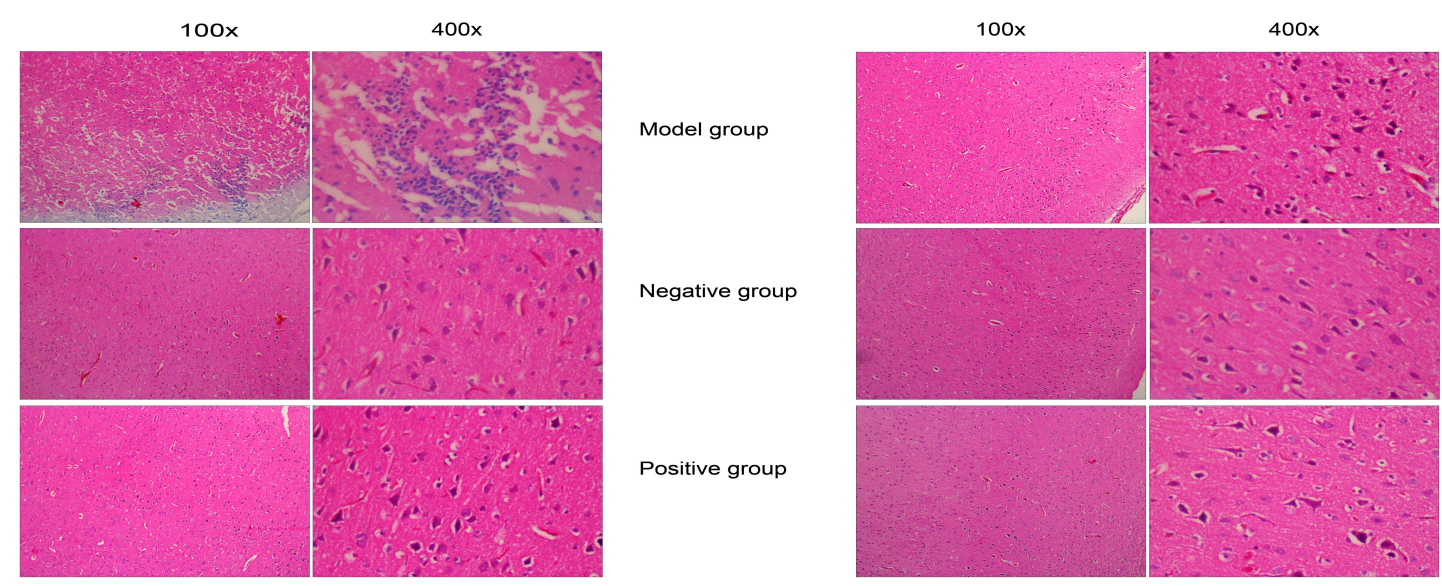

Low dose group

Medium dose group

Figure 10 Histopathology of the brain tissues with H\&E staining.

\section{Histopathology}

Histopathology of the brain tissues is shown in Figure 10. Compared with the negative group, the model group showed obvious pathological changes in the brains, mainly in the cerebral cortex, such as different degrees of oedema, focal necrosis, normal structure disappearance, increased glial proliferation in the cortex, and substantial infiltration of inflammatory cells. For the medium- and high-dose drug groups and the positive control drug group, injury to the brain tissue was significantly reduced because no oedema was evident, and no obvious inflammatory cell infiltration was observed. These results indicated that BRE-NG after intranasal administration was able to mitigate the damage associated with ischaemia/reperfusioninduced brain injury.

\section{Conclusion}

An efficient intranasal delivery platform of BRE-NP based on an ion-sensitive in situ gel was designed for bypassing the BBB and delivering therapeutics directly to the brain. BRE-NG was successfully prepared by mixing BRE-NP and $0.5 \%$ gellan gum $(\mathrm{m} / \mathrm{v})$ with favourable physiochemical properties, such as suitable $\mathrm{T}_{\text {sol-gel, }}$ higher waterholding capability, suitable expansion coefficient and slow release behaviour. The rheology results demonstrated that BRE-NG was a non-Newtonian fluid, which indicated that BRE-NG had excellent performance in terms of spreadability and bioadhesion. The bioavailability of BRENG in the brain was significantly improved due to the direct nose-to-brain route. Therefore, this nanosuspensionbased in situ gel may be a convenient and effective intranasal formulation for the administration of BRE.

\section{Acknowledgments}

The study was supported by the National Natural Science Foundation of China (No 81760715), the National Natural Science Foundation of Jiangxi (20202ACB206011), “1050” youth talent support program of Jiangxi University of traditional Chinese medicine (No 1141900605), the First-Class Discipline Project of Jiangxi University of traditional Chinese medicine (No JXSYLXK-ZHYAO089), the Science and Technology Project of Education Department of Jiangxi Province (No GJJ170749) and the Key Discipline of 2016 Young Teachers Training Projects of Jiangxi University of Traditional Chinese Medicine (No 2016jzzdxk006).

\section{Disclosure}

The authors report no conflicts of interest in this work.

\section{References}

1. Dichgans M, Pulit SL, Rosand J. Stroke genetics: discovery, biology, and clinical applications. Lancet Neurol. 2019;18:587-599. doi:10.1016/S1474-4422(19)30043-2

2. Go AS, Mozaffarian D, Roger VL, et al. Heart Disease and Stroke Statistics-2013 Update A Report From the American Heart Association. Circulation. 2013;127:E6-E245. doi:10.1161/CIR.0b013e31828124ad

3. Rhim T, Lee DY, Lee M. Drug delivery systems for the treatment of ischemic stroke. Pharm Res. 2013;30:2429-2444. doi:10.1007/s11095012-0959-2

4. Heuschmann PU, Kolominsky-Rabas PL, Roether J, et al. German Stroke Registers Study, G. Predictors of in-hospital mortality in patients with acute ischemic stroke treated with thrombolytic therapy. JAMA. 2004;292(15):1831-1838. doi:10.1001/jama.292.15.1831

5. Khan AR, Liu M, Khan MW, et al. Progress in brain targeting drug delivery system by nasal route. J Control Release. 2017;268:364-389. doi:10.1016/j.jconrel.2017.09.001

6. Kong L, X T L, Y N N, et al. Transferrin-Modified Osthole PEGylated Liposomes Travel the Blood-Brain Barrier and Mitigate Alzheimer's Disease-Related Pathology in APP/PS-1 Mice. Int J Nanomedicine. 2020;15:2841-2858. doi:10.2147/IJN.S239608 
7. Kumar NN, Lochhead JJ, Pizzo ME, et al. Delivery of immunoglobulin $\mathrm{G}$ antibodies to the rat nervous system following intranasal administration: distribution, dose-response, and mechanisms of delivery. J Control Release. 2018;286:467-484. doi:10.1016/j.jconrel.2018.08.006

8. Kozlovskaya L, Abou-Kaoud M, Stepensky D. Quantitative analysis of drug delivery to the brain via nasal route. $J$ Control Release. 2014;189:133-140. doi:10.1016/j.jconrel.2014.06.053

9. Pashirova TN, Zueva IV, Petrov KA, et al. Mixed cationic liposomes for brain delivery of drugs by the intranasal route: the acetylcholinesterase reactivator 2-PAM as encapsulated drug model. Colloid Surface B. 2018;171:358-367. doi:10.1016/j.colsurfb.2018.07.049

10. Peltonen L, Hirvonen J. Pharmaceutical nanocrystals by nanomilling: critical process parameters, particle fracturing and stabilization methods. J Pharm Pharmacol. 2010;62:1569-1579. doi:10.1111/ j.2042-7158.2010.01022.x

11. Wang Y, Zheng Y, Zhang L, et al. Stability of nanosuspensions in drug delivery. J Control Release. 2013;172:1126-1141. doi:10.1016/ j.jconrel.2013.08.006

12. Gulsun T, Borna SE, Vural I, et al. Preparation and characterization of furosemide nanosuspensions. $J$ Drug Deliv Sci Tec. 2018;45:93-100. doi:10.1016/j.jddst.2018.03.005

13. Wei S, Ma Y, Luo J, et al. Hydroxypropylcellulose as matrix carrier for novel cage-like microparticles prepared by spray-freeze-drying technology. Carbohydr Polym. 2017;157:953-961. doi:10.1016/j. carbpol.2016.10.043

14. Hao JF, Zhao J, Zhang SP, et al. Fabrication of an ionic-sensitive in situ gel loaded with resveratrol nanosuspensions intended for direct nose-to-brain delivery. Colloid Surface B. 2016;147:376-386. doi:10.1016/j.colsurfb.2016.08.011

15. Karavasili C, Fatouros DG. Smart materials: in situ gel-forming systems for nasal delivery. Drug Discov Today. 2016;21 (1):157-166. doi:10.1016/j.drudis.2015.10.016

16. Li X, Du L, Chen X, et al. Nasal delivery of analgesic ketorolac tromethamine thermo- and ion-sensitive in situ hydrogels. Int J Pharm. 2015;489 (1-2):252-260. doi:10.1016/j.ijpharm.2015.05.009

17. Guan YB, Yang DR, Nong SJ, et al. Breviscapine (BVP) inhibits prostate cancer progression through damaging DNA by minichromosome maintenance protein-7 (MCM-7) modulation. Biomed Pharmacother. 2017;93:103-116. doi:10.1016/j.biopha.2017.06.024

18. Xie J, Luo YJ, Chen YC, et al. Novel breviscapine nanocrystals modified by panax notoginseng saponins for enhancing bioavailability and synergistic anti-platelet aggregation effect. Colloid Surface B. 2019;175:333-342. doi:10.1016/j.colsurfb.2018.11.067

19. Li F, Wang X, Zhang Z, et al. Breviscapine provides a neuroprotective effect after traumatic brain injury by modulating the Nrf2 signaling pathway. J Cell Biochem. 2019;120:14899-14907. doi:10.1002/jcb.28751

20. Wang $\mathrm{C}$, Li Y, Gao S, et al. Breviscapine Injection Improves the Therapeutic Effect of Western Medicine on Angina Pectoris Patients. PLoS One. 2015;10:e0129969. doi:10.1371/journal.pone.0129969

21. Zhang MY, Fan SJ, Li LP, et al. The anti-injury effect of breviscapine injection on the hypoxic ischemic brain damage of neonatal rats and the expression of Bcl-2 and Bax. Chinese $J$ Appl Physiol. 2011;27:196-200.

22. Gao J, Chen G, He H, et al. Therapeutic Effects of Breviscapine in Cardiovascular Diseases: A Review. Front Pharmacol. 2017;8:289. doi:10.3389/fphar.2017.00289

23. Wang L, Ma Q. Clinical benefits and pharmacology of scutellarin: A comprehensive review. Pharmacol Ther. 2018;190:105-127. doi:10.1016/j.pharmthera.2018.05.006

24. Wang H, Zhang G, Ma X, et al. Enhanced encapsulation and bioavailability of breviscapine in PLGA microparticles by nanocrystal and water-soluble polymer template techniques. Eur J Pharm Biopharm. 2017;115:177-185. doi:10.1016/j.ejpb.2017.02.021

25. Lv W, Guo J, Li J, et al. Distribution of liposomal breviscapine in brain following intravenous injection in rats. Int J Pharm. 2005;306 (1-2):99-106. doi:10.1016/j.ijpharm.2005.09.012
26. Lv W, Guo J, Ping Q, et al. Comparative pharmacokinetics of breviscapine liposomes in dogs, rabbits and rats. Int J Pharm. 2008;359(1-2):118-122. doi:10.1016/j.ijpharm.2008.03.047

27. Xiong F, Xiong C, Yao J, et al. Preparation, characterization and evaluation of breviscapine lipid emulsions coated with monooleate-PEG-COOH. Int $J$ Pharm. 2011;421(2):275-282. doi:10.1016/j.ijpharm.2011.10.008

28. Wu L, Zhang J, Watanabe W. Physical and chemical stability of drug nanoparticles. Adv Drug Deliv Rev. 2011;63(6):456-469. doi:10.1016/j.addr.2011.02.001

29. Guterres SS, Beck RCR, Pohlmann AR. Spray-drying technique to prepare innovative nanoparticulate formulations for drug administration: a brief overview. Braz J Phys. 2009;39:205-209. doi:10.1590/ S0103-97332009000200013

30. Hosny KM, Hassan AH. Intranasal in situ gel loaded with saquinavir mesylate nanosized microemulsion: preparation, characterization, and in vivo evaluation. Int $J$ Pharm. 2014;475(1-2):191-197. doi:10.1016/j.ijpharm.2014.08.064

31. Cai Z, Song X, Sun F, et al. Formulation and evaluation of in situ gelling systems for intranasal administration of gastrodin. AAPS PharmSciTech. 2011;12(4):1102-1109. doi:10.1208/s12249-0119678-y

32. Hu H, Pereira J, Xing L, et al. Thermal gelation and microstructural properties of myofibrillar protein gel with the incorporation of regenerated cellulose. LWT. 2017;86:14-19. doi:10.1016/j.lwt.2017.07.015

33. Na L, Mao S, Wang J, et al. Comparison of different absorption enhancers on the intranasal absorption of isosorbide dinitrate in rats. Int $J$ Pharm. 2010;397:59-66. doi:10.1016/j.ijpharm.2010. 06.048

34. Yang ZZ, Zhang YQ, Wang ZZ, et al. Enhanced brain distribution and pharmacodynamics of rivastigmine by liposomes following intranasal administration. Int $J$ Pharm. 2013;452(1-2):344-354. doi:10.1016/j.ijpharm.2013.05.009

35. Wang F, Yang Z, Liu M, et al. Facile nose-to-brain delivery of rotigotine-loaded polymer micelles thermosensitive hydrogels: in vitro characterization and in vivo behavior study. Int J Pharm. 2020;577:119046. doi:10.1016/j.ijpharm.2020.119046

36. Cong W, Shen L, Xu D, et al. Solid dispersion tablets of breviscapine with polyvinylpyrrolidone K30 for improved dissolution and bioavailability to commercial breviscapine tablets in beagle dogs. Eur J Drug Metab Pharmacokinet. 2014;39(3):203-210. doi:10.1007/ s13318-013-0150-0

37. Fatouh AM, Elshafeey AH, Abdelbary A. Agomelatine-based in situ gels for brain targeting via the nasal route: statistical optimization, in vitro, and in vivo evaluation. Drug Deliv. 2017;24(1):1077-1085. doi:10.1080/10717544.2017.1357148

38. Goncalves J, Bicker J, Gouveia F, et al. Nose-to-brain delivery of levetiracetam after intranasal administration to mice. Int J Pharm. 2019;564:329-339. doi:10.1016/j.ijpharm.2019.04.047

39. Kitagawa K, Matsumoto M, Tsujimoto Y, et al. Amelioration of hippocampal neuronal damage after global ischemia by neuronal overexpression of BCL-2 in transgenic mice. Stroke. 1998;29 (12):2616-2621. doi:10.1161/01.STR.29.12.2616

40. Nair A, Khunt D, Misra M. Application of quality by design for optimization of spray drying process used in drying of Risperidone nanosuspension. Powder Technol. 2019;342:156-165. doi:10.1016/j. powtec.2018.09.096

41. Wang $R$, Wang $X$, Jia $X$, et al. Impacts of particle size on the cytotoxicity, cellular internalization, pharmacokinetics and biodistribution of betulinic acid nanosuspensions in combined chemotherapy. Int $J$ Pharm. 2020;588:119799. doi:10.1016/j. ijpharm.2020.119799

42. Chen Y, Gui Y, Luo Y, et al. Design and evaluation of inhalable nanocrystals embedded microparticles with enhanced redispersibility and bioavailability for breviscapine. Powder Technol. 2020;377:128-138. doi:10.1016/j.powtec.2020.08.040 
43. Rajput AP, Butani SB. Resveratrol anchored nanostructured lipid carrier loaded in situ gel via nasal route: formulation, optimization and in vivo characterization. J Drug Deliv Sci Tec. 2019;51:214-223. doi:10.1016/j.jddst.2019.01.040

44. Cao SL, Zhang QZ, Jiang XG. Preparation of ion-activated in situ gel systems of scopolamine hydrobromide and evaluation of its antimotion sickness efficacy. Acta Pharmacol Sin. 2007;28:584-590. doi:10.1111/j.1745-7254.2007.00540.x

45. Shah V, Sharma M, Pandya R, et al. Quality by Design approach for an in situ gelling microemulsion of Lorazepam via intranasal route. Mater Sci Eng C Mater Biol Appl. 2017;75:1231-1241. doi:10.1016/ j.msec.2017.03.002

46. Nazar H, Fatouros DG, van der Merwe SM, et al. Thermosensitive hydrogels for nasal drug delivery: the formulation and characterisation of systems based on N-trimethyl chitosan chloride. Eur J Pharm Biopharm. 2011;77:225-232. doi:10.1016/j.ejpb.2010.11.022
47. Inoue D, Furubayashi T, Tanaka A, et al. Quantitative estimation of drug permeation through nasal mucosa using in vitro membrane permeability across Calu-3 cell layers for predicting in vivo bioavailability after intranasal administration to rats. Eur J Pharm Biopharm. 2020;149:145-153. doi:10.1016/j.ejpb.2020.02.004

48. Mei D, Mao SR, Sun W, et al. Effect of chitosan structure properties and molecular weight on the intranasal absorption of tetramethylpyrazine phosphate in rats. Eur J Pharm Biopharm. 2008;70:874-881. doi:10.1016/j.ejpb.2008.06.031

49. Chatterjee B, Gorain B, Mohananaidu K, et al. Targeted drug delivery to the brain via intranasal nanoemulsion: available proof of concept and existing challenges. Int $J$ Pharm. 2019;565:258-268. doi:10.1016/j.ijpharm.2019.05.032

50. Agrawal M, Saraf S, Saraf S, et al. Stimuli-responsive In situ gelling system for nose-to-brain drug delivery. $J$ Controlled Release. 2020;327:235-265. doi:10.1016/j.jconrel.2020.07.044
International Journal of Nanomedicine

\section{Publish your work in this journal}

The International Journal of Nanomedicine is an international, peerreviewed journal focusing on the application of nanotechnology in diagnostics, therapeutics, and drug delivery systems throughout the biomedical field. This journal is indexed on PubMed Central, MedLine, CAS, SciSearch ${ }^{\mathbb{R}}$, Current Contents ${ }^{\mathbb{B}} /$ Clinical Medicine, $^{2}$
Dovepress

Journal Citation Reports/Science Edition, EMBase, Scopus and the Elsevier Bibliographic databases. The manuscript management system is completely online and includes a very quick and fair peer-review system, which is all easy to use. Visit http://www.dovepress.com/ testimonials.php to read real quotes from published authors. 